\title{
Editorial \\ Hot Research Topics in the Biomass Catalysis Section of the Catalysts Journal in 2018 and 2019
}

\author{
Francesco Mauriello $^{1, *(D)}$ and Anna Maria Raspolli Galletti ${ }^{2, *(D)}$ \\ 1 Dipartimento DICEAM, Università Mediterranea di Reggio Calabria, Loc. Feo di Vito, \\ I-89122 Reggio Calabria, Italy \\ 2 Department of Chemistry and Industrial Chemistry, University of Pisa, Via Giuseppe Moruzzi 13, \\ I-56124 Pisa, Italy \\ * Correspondence: francesco.mauriello@unirc.it (F.M.); anna.maria.raspolli.galletti@unipi.it (A.M.R.G.)
}

check for

updates

Citation: Mauriello, F.; Galletti, A.M.R. Hot Research Topics in the Biomass Catalysis Section of the Catalysts Journal in 2018 and 2019. Catalysts 2021, 11, 153.

https://doi.org/10.3390/ catal11020153

Received: 18 January 2021

Accepted: 20 January 2021

Published: 22 January 2021

Publisher's Note: MDPI stays neutral with regard to jurisdictional claims in published maps and institutional affiliations.

Copyright: (c) 2021 by the authors. Licensee MDPI, Basel, Switzerland. This article is an open access article distributed under the terms and conditions of the Creative Commons Attribution (CC BY) license (https:/ / creativecommons.org/licenses/by/ $4.0 /)$.

\section{Introduction}

In recent years, many researchers have contributed to the "Biomass Catalysis" section of the journal Catalysts (MDPI). With this Editorial, we would like to acknowledge all contributions published so far highlighting, in particular, the top 10 high-cited papers in the two-year period 2018-2019 that can be considered, rightly so, as hot topics in the field of biomass catalysis research. Most recent advances in the catalytic conversion of biomass into valuable platform chemicals will be discussed in the following paragraph emphasizing, at the same time, the remaining challenges in this field.

\section{Hot Topics and Challenges of Biomass Catalysis}

The transition from a fossil-based economy to a bio-based society represents a fundamental goal to contrast key global issues, such as climate change and environmental pollution, and to reduce the strong dependency on fossil resources. Therefore, the replacement of fossil-based fuels and materials with biofuels and bioproducts is of paramount importance.

One of the main drawbacks of the catalytic valorization of lignocellulosic biomass is the elevated oxygen content of its three main components (cellulose, hemicellulose and lignin) that makes biomass and their derived compounds acidic and unstable, thus making themnon-effective alternatives to fossil feedstocks [1]. Therefore, lots of research has been devoted towards the development of reductive upgrading technologies based on hydrogenation and hydrogenolysis reactions of the intermediates obtained by biomass depolymerization and dehydration [2-4].

In this context, cellulose- and hemicellulose-derived furans, namely, furfural and 5-hydroxymethylfurfural (HMF), already represent an important class of biobased building block for modern biorefineries [5,6]. In particular, the hydrogenation of furfural allows for the production of several biofuels and biobased fuel additives including (tetrahydro)furfuryl alcohol, 2-methyl(tetrahydro)furan, levulinates and diols. In their review, Len and co-workers highlight recent advances in the preparation of (tetrahydro)furfuryl alcohol and 2-methyl(tetrahydro)furan starting from furfural [7]. A complete overview of the different reaction pathways occurring on the catalyst surface (adopting both noble and non-noble metal catalytic systems) as well as of the influence of the reaction conditions adopted is nicely discussed [7]. Authors pointed out that, although lab-scale studies already allow for the selectiveproduction of various furfural hydrogenation products, more efforts should be accomplished to scale-up furfural reductive valorizationviacontinuous flow technologies.

When the dehydration of the cellulosic fraction of biomass is performed under harsher acid conditions, the intermediate HMF is rehydrated to give levulinic acid and formic acid in equimolar amounts. Levulinic acid (LA) represents a strategic platform chemical which 
has been included within the list of "top value added chemicals from biomass" and is receiving increasing attention since it can be successfully converted into more added-value bio-products including biofuels, solvents, plasticizers, polymers and fine chemicals [8].

In particular, alkyl levulinates are outstanding biofuels which can be blended with gasoline or diesel/biodiesel withpositive environmental effects [9]. Yang et al. optimized the esterification of LA with n-butanol to obtain butyl levulinate with high yield and total selectivity using a sulfonated amorphous carbon prepared from theincomplete carbonization of glucose [10]. This catalyst showed much higher catalytic activity not only with respect to an analogous catalyst prepared using a commercial active carbon but also to the commercial heterogeneous acid catalysts HZSM-5, Amberlyst-15 and Nafion-212. This result was ascribed tothe morphology of the synthesized carbon-support which is easier to be sulfonated, resulting in higher $-\mathrm{SO}_{3} \mathrm{H}$ density. Moreover, its swelling capacity provides good access of reactants to the $-\mathrm{SO}_{3} \mathrm{H}$ sites located in the carbon matrix. The strong acid strength and high $-\mathrm{SO}_{3} \mathrm{H}$ density, in cooperation with weak acid sites $(-\mathrm{COOH}$ and phenolic $-\mathrm{OH}$ ) attached on the carbon surface, are held responsible for the ascertained excellent performances.

The hydrogenation of levulinic acid or alkyl levulinates affords $\gamma$-valerolactone (GVL), a valuable cyclic ester that can be used as a platform chemical, a green solvent and a promising additive for petroleum-derived fuels $[11,12]$. The economic and environmental sustainability of the industrial synthesis of levulinic acid strongly depend on the adopted starting material, cellulose-rich raw or waste biomasses being preferred in the recent research [13]. Raw materials generally need a pretreatment step in order to remove extractives and hemicelluloses and increase the selectivity of the hydrothermal process to levulinic acid. In this context Rivas et al. studied Eucalyptus globulus wood as starting material for levulinic acid and $\gamma$-valerolactone synthesis [14]. Raw wood samples were subjected to a preliminary aqueous treatment to remove water-soluble valuable extractives and hemicelluloses, then the resulting solid (mainly containing cellulose and lignin) was employed as a substrate for the production of levulinic and formic acid by acid-catalyzed conversion. The cross-flow approach allowed forobtaining highly concentrated levulinic acid solutions which were then employed for cascade hydrogenation to $\gamma$-valerolactone using a commercial $5 \% \mathrm{Ru} / \mathrm{C}$ catalyst. The optimization of the hydrogenation step allowed forreaching yields of $\gamma$-valerolactone in the range of $85-90 \mathrm{~mol} \%$, a valuable result for a cascade process starting from a real biomass.

A cascade strategy for the catalytic valorization of aqueous solutions of levulinic acid and of $\gamma$-valerolactone to 2-methyltetrahydrofuran or to monoalcohols (2-butanol and 2-pentanol) has been optimized in the paper of Licursi and co-workers [15]. The authors evidenced that commercial ruthenium and rhenium catalysts supported on carbon, in the presence of niobium phosphate as acid co-catalyst, gave good performances in the selective hydrogenation of $\gamma$-valerolactone and levulinic acid to 2-methyltetrahydrofuran. On the other hand, when the acid zeolite HY was employed with Ru/C catalyst, the highly selective production of 2-butanol from $\gamma$-valerolactone and levulinic acid was ascertained. This paper evidenced as the choice of both the catalytic system and the reaction conditions can be tuned to switch the process towards the selective production of 2-methyltetrahydrofuran or monoalcohols. The interest towards this topic is increasing due to the wide potential applications of the target products as green solvents, platform chemicals and biobased additives for fuels.

In the above-discussed processes on the hydrothermal treatments of biomasses for the production of levulinic acid and its further reductive upgrading, lignin is generally recovered as a carbonaceous hydrochar, hitherto considered only asa waste fraction andgenerally employed only for energy recovery. Alternatively, the recovered hydrochar, which contains moieties deriving mainly from lignin and also from residual polysaccharides, is rich in aromatic, hydroxylic and carboxylic functionalities [16], andincreasing examples of its exploitation for smart applications as soil amendment, for the synthesis of energy storage 
materials, flexible polyurethane foams and catalytic materials have been reported in these last years.

More generally, the use of carbonaceous chars obtained from the thermochemical conversion of biomass as catalysts or catalyst supports surely represents a very hot topic. In this context, Cheng et al. have deeply reviewed the synthesis and activation of biochars as well as their catalytic applications [17]. The characteristics of biochars obtained from conventional pyrolysis and from hydrothermal carbonization (HTC) were compared, evidencing the HTC advantages. The catalytic performances of the different biochars were also analyzed, focusing on their application to three strategic routes for biofuels production, i.e., biomass hydrolysis, biodiesel production and tar reduction. This analysis suggests that a purpose-driven industrial production of biochar-based catalysts can be efficiently combined with the production of different biofuels in an integrated biorefinery plant, with an increase in its economic and environmental sustainability.

Vakros reviewed the application of different pyrolytic biochars as catalysts for the transesterification step of lipids to give biodiesel [18]. The review has focused the attention on the performances of acid and basic activated biochars derived from raw or waste biomasses. In fact, the utilization of biomass waste, in the form of biochar, for the production of solid catalysts allows for reducing the cost of the catalyst and can also represent a disposal of biomass waste. Sulfonated biochars characterized by the high Bronsted acidity of $-\mathrm{SO}_{3} \mathrm{H}$ groups into the biochar surface offer excellent performances for lipid feeds with a high concentration of acids, such as cook waste oils. On the other hand, in contrast with the acid-modified systems, basic biochars can be applied only on oils without significant acidity. They exhibit significant activity affording high biodiesel yield but the requirement of high purity of the feed represents a significant issue [18].

Among the different components of the lignocellulosic biomass, lignin still remains highly underutilized. Not only the lignin fraction of the raw biomass but also those deriving from the pulp and paper industry are exploited to a low extent, whilst the most part is burned as a low value fuel. In this regard, in the last years, several contributions focused on the valorization of lignin and their derived molecules for the sustainable production of aromatic compounds havebeen published [19-21]. Lignin derivatives include aromatic ethers, phenols, guaiacols, syringols and eugenol that can be further valorized into added value compoundsviareductive or oxidative catalytic processes [22]. Eugenol, for example, can be upgraded into several valued added compounds through catalytic hydrogenation, hydrodeoxygenation and hydrocracking processes by using magnetic $\mathrm{Ru} / \mathrm{C}-\mathrm{Fe}_{2} \mathrm{O}_{3}$ catalytic systems [22]. In an article from Bjelić et al., it is shown that the product distribution is significantly affected by the annealing temperature $\left(0,300,500,600\right.$, and $\left.750{ }^{\circ} \mathrm{C}\right)$ of the $\mathrm{Ru} / \mathrm{C}-\mathrm{Fe}_{2} \mathrm{O}_{3}$ catalysts. It was demonstrated that the yield of hydrogenation products increases by increasing the annealing temperature with the $\mathrm{Ru} / \mathrm{C}-\mathrm{Fe}_{2} \mathrm{O}_{3}$ system (treated at $600{ }^{\circ} \mathrm{C}$ ) showing superior catalytic performance in terms of the deoxygenation of saturated intermediates with respect to the commercially available $\mathrm{Ru} / \mathrm{C}$ [22].

Hydrodeoxygenation reactions have been largely adopted also for the production of biodiesel starting from waste oils and fats [23]. The recovery and the use of waste oils and fats as starting materials for the preparation of second-generation biofuels is surely one of the most promising catalytic approachesto overcomeenvironmental and economicproblems related to edible biomasses also sadly known as the "food versus fuel" issue. Therefore, this field of biomass catalysis has been largely investigated by academia and industry researchers with both heterogeneous and homogenous catalytic systems. Fierro and coworkers, for example, review current trends in the use of catalysts based on transition metal phosphides (TMPs) in the synthesis of biofuels (green or renewable diesel) from biowaste oils and fats [24]. TMP catalysts are characterized by electronic properties similar to those of noble metals being, at the same time, more stable and resistant to the presence of water in the reaction media. The review also focuseson the influence of the nature of active phases and effects of phosphorous, promoters, and preparation methods on reactivity [24]. 
Together with classic reductive processes that imply the adoption of pressurized molecular hydrogen, the use of an indirect $\mathrm{H}$-source for reducing the oxygen content in lignocellulosic biomasses, widely known as catalytic transfer hydrogenation/hydrogenolysis reactions $(\mathrm{CTH})$, is receiving increasing attention $[25,26]$. Espro et al. presented this relevant research area in their review article presenting recent advances in the CTH of cellulose, hemicellulose, lignin, and of their derived model molecules promoted by heterogeneous catalytic systems [25].The authors summarized several catalytic processes promoted by different $\mathrm{H}$-donor molecules, ranging from simple primary-secondary alcohols (methanol, ethanol, and 2-propanol) to formic acid, highlighting the reaction pathwaysthat occur at the molecular level of $\mathrm{CTH}$ reactions of polyols, ethersand furan derivatives.

Together with reductive catalytic processes, the oxidative upgrading of biomasses has also attracted the attention of many researchers [27]. The selective oxidation of bioderived alcohols and polyols to carbonyl compounds into aldehydes/ketones, acids and esters represents an important catalytic reaction for the industrial preparation of drugs, cosmetics and agrochemicals compounds [28]. For example, the oxidation of glycerol (the major byproduct in biodiesel production) is another research challenge since it permits obtaining a wide range of valuable commodity chemicals $[29,30]$.

In an article from Xue et al., the role of bismuth in hydrotalcite-supported platinum catalysts $(\mathrm{Pt}-\mathrm{Bi} / \mathrm{HT})$ as a promoter of the oxidation of glycerol to dihydroxyacetone is presented [30]. The incorporation of Bi species into $\mathrm{Pt} / \mathrm{HT}$ significantly enhances the conversion of glycerol as well as the selectivity towards dihydroxyacetone. The authors, through a detailed physico-chemical analysis by means of XRD, XPS and HR-TEM, demonstrated that the promotional role of Bi species is dominated by the geometrical effect and the occurrence of strong hydrogen bonds between the $\mathrm{Cl}$ ion of $\mathrm{BiOCl}$ on the surface of the support and the primary - $\mathrm{OH}$ group of the glycerol molecule.

Funding: This research received no external funding.

Conflicts of Interest: The authors declare no conflict of interest.

\section{References}

1. Zhou, C.-H.; Xia, X.; Lin, C.-X.; Tong, D.-S.; Beltramini, J. Catalytic conversion of lignocellulosic biomass to fine chemicals and fuels. Chem. Soc. Rev. 2011, 40, 5588-5617. [CrossRef] [PubMed]

2. De, S.; Saha, B.; Luque, R. Hydrodeoxygenation processes: Advances on catalytic transformations of biomass-derived platform chemicals into hydrocarbon fuels. Bioresour. Technol. 2015, 178, 108-118. [CrossRef] [PubMed]

3. Ruppert, A.M.; Weinberg, K.; Palkovits, R. Hydrogenolysis goes bio: From carbohydrates and sugar alcohols to platform chemicals. Angew. Chem. Int. Ed. 2012, 51, 2564-2601. [CrossRef] [PubMed]

4. Xu, C.; Paone, E.; Rodríguez-Padrón, D.; Luque, R.; Mauriello, F. Reductive catalytic routes towards sustainable production of hydrogen, fuels and chemicals from biomass derived polyols. Renew. Sustain. Energy Rev. 2020, 127, 109852. [CrossRef]

5. Li, X.; Jia, P.; Wang, T. Furfural: A promising platform compound for sustainable production of C4and C5chemicals. ACS Catal. 2016, 6, 7621-7640. [CrossRef]

6. Xu, C.; Paone, E.; Rodríguez-Padrón, D.; Luque, R.; Mauriello, F. Recent catalytic routes for the preparation and the upgrading of biomass derived furfural and 5-hydroxymethylfurfural. Chem. Soc. Rev. 2020, 49, 4273-4306. [CrossRef] [PubMed]

7. Wang, Y.; Zhao, D.; Rodríguez-Padrón, D.; Len, C. Recent advances in catalytic hydrogenation of furfural. Catalysts 2019, 9, 796. [CrossRef]

8. Artz, J.; Palkovits, R. Cellulose-based platform chemical: The path to application. Curr. Opin. Green Sustain. Chem. 2018, 14, 14-18. [CrossRef]

9. Antonetti, C.; Gori, S.; Licursi, D.; Pasini, G.; Frigo, S.; López, M.; Parajó, J.C.; Galletti, A.M.R. One-pot alcoholysis of the lignocellulosic eucalyptus nitens biomass to n-butyl levulinate, a valuable additive for diesel motor fuel. Catalysts 2020, 10, 509. [CrossRef]

10. Yang, J.; Li, G.; Zhang, L.; Zhang, S. Efficient production of n-butyl levulinate fuel additive from levulinic acid using amorphous carbon enriched with oxygenated groups. Catalysts 2018, 8, 14. [CrossRef]

11. Liguori, F.; Moreno-Marrodan, C.; Barbaroa, P. Environmentally friendly synthesis of \& gamma; -valerolactone by direct catalytic conversion of renewable sources. ACS Catal. 2015, 5, 1882-1894. [CrossRef]

12. Tabanelli, T.; Paone, P.; Blair Vásquez, P.; Pietropaolo, R.; Cavani, F.; Mauriello, F. Transfer hydrogenation of methyl and ethyl levulinate promoted by a zro2 catalyst: Comparison of batch vs continuous gas-flow conditions. ACS Sustain. Chem. Eng. 2019, 7 , 9937-9947. [CrossRef] 
13. Antonetti, C.; Licursi, D.; Galletti, A.M.R. New intensification strategies for the direct conversion of real biomass into platform and fine chemicals: What are the main improvable key aspects? Catalysts 2020, 10, 961. [CrossRef]

14. Rivas, S.; RaspolliGalletti, A.M.; Antonetti, C.; Licursi, D.; Santos, V.; Parajó, J.C. A biorefinery cascade conversion of hemicellulosefree eucalyptus globulus wood: Production of concentrated levulinic acid solutions for $\gamma$-valerolactone sus-tainable preparation. Catalysts 2018, 8, 169. [CrossRef]

15. Licursi, D.; Antonetti, C.; Fulignati, S.; Giannoni, M.; RaspolliGalletti, A.M. Cascade strategy for the tunable catalytic val-orization of levulinic acid and $\gamma$-valerolactone to 2-methyltetrahydrofuran and alcohols. Catalysts 2018, 8, 277. [CrossRef]

16. Licursi, D.; Antonetti, C.; Bernardini, J.; Cinelli, P.; Coltelli, M.B.; Lazzeri, A.; Martinelli, M.; RaspolliGalletti, A.M. Characterization of the Arundo Donax L. solid residue from hydrothermal conversion: Comparison with technical lignins and application perspectives. Ind. Crop. Prod. 2015, 76, 1008. [CrossRef]

17. Cheng, F.; Li, X. Preparation and application of biochar-based catalysts for biofuel production. Catalysts 2018, 8, 346. [CrossRef]

18. Vakros, J. Biochars and their use as transesterification catalysts for biodiesel production: A short review. Catalysts 2018, 8, 562. [CrossRef]

19. Paone, E.; Tabanelli, T.; Mauriello, F. The rise of lignin biorefinery. Curr. Opin. Green Sustain. Chem. 2020, 24, 1-6. [CrossRef]

20. Wong, S.S.; Shu, R.; Zhang, J.; Liu, H.; Yan, N. Downstream processing of lignin derived feedstock into end products. Chem. Soc. Rev. 2020, 49, 5510-5560. [CrossRef]

21. Paone, E.; Beneduci, A.; Corrente, G.A.; Malara, A.; Mauriello, F. Hydrogenolysis of aromatic ethers under lignin-first condi-tions. Mol. Catal. 2020, 497, 111228.

22. Bjelić, A.; Grilc, M.; Gyergyek, S.; Kocjan, A.; Makovec, D.; Likozar, B. Catalytic hydrogenation, hydrodeoxygenation, and hydrocracking processes of a lignin monomer model. Catalysts 2018, 8, 425. [CrossRef]

23. Khodadadi, M.R.; Malpartida, I.; Tsang, C.-W.; Lin, C.S.K.; Len, C. Recent advances on the catalytic conversion of waste cooking oil. Mol. Catal. 2020, 494, 111128. [CrossRef]

24. Alvarez-Galvan, M.C.; Campos-Martin, J.M.; Fierro, J.L.G. Transition metal phosphides for the catalytic hydrodeoxygen-ation of waste oils into green diesel. Catalysts 2019, 9, 293. [CrossRef]

25. Espro, C.; Gumina, B.; Szumelda, T.; Paone, E.; Mauriello, F. Catalytic transfer hydrogenolysis as an effective tool for the reductive upgrading of cellulose, hemicellulose, lignin, and their derived molecules. Catalysts 2018, 8, 313. [CrossRef]

26. Gilkey, M.J.; Xu, B. Heterogeneous catalytic transfer hydrogenation as an effective pathway in biomass upgrading. ACS Catal. 2016, 6, 1420-1436. [CrossRef]

27. Zhang, Z.; Huber, G.W. Catalytic oxidation of carbohydrates into organic acids and furan chemicals. Chem. Soc. Rev. 2018, 47, 1351-1390. [CrossRef]

28. Védrine, J.C. Metal oxides in heterogeneous oxidation catalysis: State of the art and challenges for a more sustainable world. ChemSusChem 2019, 12, 577-588. [CrossRef]

29. Dodekatos, G.; Schünemann, S.; Tüysüz, H. Recent advances in thermo-, photo-, and electrocatalytic glycerol oxidation. ACS Catal. 2018, 8, 6301-6333. [CrossRef]

30. Xue, W.; Wang, Z.; Liang, Y.; Xu, H.; Liu, L.; Dong, J. Promoting role of bismuth on hydrotalcite-supported platinum catalysts in aqueous phase oxidation of glycerol to dihydroxyacetone. Catalysts 2018, 8, 20. [CrossRef] 